\title{
LOS SILENCIOS DE LA TORTURA EN CHILE*
}

\author{
The Silences of Torture in Chile
}

\section{JOSÉ SANTOS HERCEG}

Universidad de Santiago de Chile

\section{RESUMEN}

El presente texto busca mostrar que el silencio tuvo y tiene un papel central en el fenómeno de la tortura en Chile. Callan las autoridades dictatoriales sobre su ocurrencia, callan los perpetradores directos y callan todos los que están en el "pacto de silencio", así como también los que se benefician de ella. Calla el torturador cuando está interrogando con el objeto de extremar el terror, pero calla también la víctima que no delata. Calla el sobreviviente que no consigue articular un relato sobre lo vivido, calla todo el mundo aterrorizado ante la amenaza de ser torturado. Callan, finalmente las autoridades transicionales que buscan poner un punto final a la investigación sobre un pasado doloroso.

Palabras clave: tortura, silencio, Chile, dictadura.

\begin{abstract}
The aim of this manuscript is to argue that the silence played a very important role in the phenomenon of torture in Chile. The dictatorial authorities were silent about its occurrence, the direct perpetrators are silent and all those who are part of the "pact of silence", as well as those who benefited from it. The torturer is silent when he is interrogating with the aim of spreading terror, but so is the victim who does not inform on the crime. The survivor who cannot articulate a story about his or her experience is silent, and everyone is terrified by the threat of being tortured. Finally, the transitional authorities who seek to put an end to the investigation into a painful past remain silent.
\end{abstract}

Keywords: torture, silence, Chile, dictatorship. 


\section{INTRODUCCIÓN}

Lo que hoy llamamos tortura ha tenido a lo largo de la historia muy diferentes modulaciones (Mellor 1949; Lujan 1972; Forner 1990; Lyons 2005). En esta oportunidad atenderemos solamente a una de ellas: la que se ejerce institucionalmente desde el Estado, es decir, aquel modo de la tortura que practican los órganos como policías, servicios secretos, militares, etc. Este tipo de tortura es especialmente compleja y contradictoria por el hecho de que, como ha escrito Calveiro, el Estado de Derecho y el Estado de Excepción, lejos de excluirse, parecen convivir, superponerse: "Es un Estado de doble cara, reversible, que aparece y desaparece el derecho según el rostro de su contraparte" (2008: 92). Interesa, en particular, adentrarnos en la práctica de la tortura institucional en Chile. Fenómeno que ha estado presente en el país desde siempre y que se traslada al período dictatorial casi naturalmente. Vidal señala expresamente que "la tortura ha sido una práctica inmemorial en Chile, aplicada a los delincuentes comunes en el circuito policial-judicial- carcelario; de allí la dictadura la trasladó al campo de lo político con la transferencia de personal policial a los servicios de seguridad militar" (2000: 25. Cfr. Loveman y Lira 2004: 187).

Si bien se la identifica con los regímenes dictatoriales y su énfasis en prácticas coercitivas violentas, la tortura no es, sin embargo, un fenómeno que se circunscriba al pasado reciente, sino que tiene una clara actualidad, sobrepasando los contextos represivos e instalándose en marcos democráticos. Contrario a lo que podría pensarse, dice Calveiro, "[1]a expansión de las democracias globalizadas no ha desalentado la decisión política de torturar sino todo lo contrario y nos enfrentamos hoy incluso a la exposición mediática y desvergonzada de dichas prácticas, frente a la tolerancia y complicidad de las más orgullosas democracias" (2008: 75). En Chile, sin ir más lejos, el fenómeno tiene una actualidad innegable. Juana Aguilera constata que "[h]oy las noticias locales nos hablan casi cotidianamente de la tortura" (2016), y enumera algunos casos ocurridos en el último tiempo en donde queda de manifiesto que es una práctica habitual, cuyas víctimas son dirigentes estudiantiles, ciudadanos extranjeros, comuneros o dirigentes mapuche, etc.

Pese a su ocurrencia palmaria y sostenida, la tortura institucional en Chile fue y es un fenómeno atravesado por el silencio. López y Otero señalan que "[u]na de las tantas paradojas que rodea la existencia de la tortura es que, no obstante su recurrencia, de ella prácticamente no se habla" (1989: 11). De allí el acertado título del libro compilado por Patricia Verdugo llamado De la tortura no se habla (2004). En particular el tema ha estado prácticamente ausente en casi todas las áreas del conocimiento. Las excepciones están en el ámbito de la atención primaria a las víctimas: la salud mental (Rojas 1989, 1996; Pesutic 1996; Reszcynski et al. 1991) y lo jurídico (Domínguez 1990; Fresno 1990; García Villegas 1990; Galiano 2001). Vidal lo dice expresamente a comienzos del milenio: "Hasta ahora el entendimiento de la tortura en Chile ha estado restringido a los campos especializados de la psicoterapéutica y de los estudios jurídicos" (2000: 9) y Egaña lo corrobora unos años después (2005: 8). 
Fuera de las áreas mencionadas es muy poco lo que se ha investigado y discutido sobre la tortura, aunque es posible rastrear algunos intentos por comprender el fenómeno desde otras disciplinas de las humanidades y las Ciencias Sociales. Cuando expiraba el período dictatorial, aparecieron un par de textos que se podrían mencionar como inaugurales en cuanto al desarrollo teórico sobre el tema (Rojas 1988; López y Otero 1989; Madariaga 1989). La publicación de estos libros podría haber augurado que el problema ocuparía un lugar privilegiado en adelante, pero los trabajos que se desmarcan del ámbito de la salud mental y de lo jurídico publicados durante los años 90 resultan ser muy escasos (Forner 1990; Reszcynski, Rojas y Barceló 1991; Westin 1994; Guerrero 1999). La primera década del mileno no presenta un mejor panorama: solo aparecen algunos pocos libros (Vidal 2000; Verdugo 2004; Moya 2005). Hace más de diez años de la publicación de estos últimos textos sobre la tortura en Chile y hasta hoy encontramos solo una serie de artículos (Osorio 2012; Bulo 2013; Santos-Herceg 2015; Sepúlveda 2016; Yuing 2016; Martínez 2017; Andueza 2017), algunas tesis de grado (Egaña 2005; Moreno 2008; Ahumada 2011; Palacios 2011; Rojas 2013; Álvarez y Vega 2014; Navarro 2015) y otras de posgrado (Zapata 2008; Hevia 2014).

La existencia de estos trabajos hace posible que el tema de la tortura no desaparezca del todo del ámbito de la investigación chilena en Ciencias Sociales y Humanidades, sin embargo, no logran constituir una línea fuerte de trabajo sistemático y contundente. Los intelectuales chilenos seguimos, hasta hoy, muy callados y manteniendo un tozudo silencio respecto del tema. Este, por supuesto, está lejos de ser el único silencio vinculado con el fenómeno de la tortura. El silencio, de hecho, no es tan solo un elemento más de la tortura, sino que lo atraviesa por completo tomando múltiples y diferentes modulaciones, convirtiéndose en un componente esencial de su práctica.

\section{INSTRUMENTO}

\section{Los verdugos}

El silencio es, en primer lugar, una herramienta central durante el proceso de tortura mismo, aunque tiene sentidos contrapuestos. Es, por una parte, utilizado por los torturadores para hacer sufrir, para causar daños. Tricot, al hacer el análisis de los principios básicos que debe considerar un torturador incluye, entre otros, la "utilización de los silencios" (1990: 4). En efecto, éste tiene un papel central en tanto que la pericia de los verdugos se juega en gran medida en la capacidad de administrarlo. La tortura, como se sabe, comienza antes del primer golpe, antes de la primera amenaza, cuando se da inicio al llamado "ablandamiento". Se trata de lo que Reszcynski, Rojas y Barceló han denominado "situación condicionada", es decir, "una situación especialmente preparada de acuerdo a la técnica de tortura que se va a aplicar y para que ésta sea más 
eficaz" (1991: 122). Dicha situación tiene un primer momento durante el cual el silencio tiene un papel central en varios sentidos.

Por una parte, el silencio inicial adquiere la forma del no ser llamado. La espera antes de ser llevado a la tortura es, según los testimonios, intolerable: el no escuchar su nombre en la lista de los convocados provoca grandes niveles de ansiedad. Sánchez habla de "sufrir la incertidumbre de esperar día tras día el llamado a interrogatorio" (2014: 126). El mismo autor relata en su testimonio la ocasión en que sacaron a unos prisioneros de su cabaña y escuchó la siguiente exclamación: "iiiPor la chucha!!! -dijo uno-. iii¿¿Cuándo mierda me tocará a mí??!!! iiiQuiero salir de una vez por todas de esta weá, sea pa' bien o pa' mal!!!" (2014: 107). En este mismo sentido, al ser informado de que posiblemente sería interrogado al día siguiente, Cozzi hace una sorprendente pregunta: “-¿Por qué no es seguro? -le pregunté al suboficial. -Si no va mañana irá pasado mañana -respondió. -¿Usted puede hacer lo posible para que sea mañana?" (2000: 58). Patricio Santelices incluso se ofrece de voluntario para la tortura (2008: 56).

Por otra parte, el silencio forma parte de lo que en el Manual Kubark se denomina "deprivación de estímulos sensoriales" (1963: 187). El procedimiento consiste en dejar al detenido aislado sin que tenga ningún estímulo. En este contexto, el silencio es esencial: deprivación sonora. La incomunicación es como se hace efectiva. El silencio es la norma, pues la orden era siempre permanecer callado. En los testimonios de los prisioneros se reproducen muchas veces los dichos de los guardias, y entre ellos la orden de callar es, quizás, la más recurrente: "iQuédate callado conchetumadre o te sacamos al tiro a vos también!" (Ahumada 2011: 95); “¿Qué te pasa, huevona? ¡Cállense!” (Arce 1993: 122); “QQuédense callados, mierda!" (Bonefoy 2003: 26). La incomunicación y el aislamiento, por su parte, son consideradas en sí misma formas de tortura (Neumann y Machiavello 1990). Nubia Becker cuenta que entre las detenidas hablaban de sus respectivas experiencias de tortura. Según su relato, una de ellas "cayó de las primeras; estuvo incomunicada más de un mes y casi se volvió loca" (1987: 23).

También el silencio contribuye a la implementación de otros métodos de interrogación propuestos por el Manual Kubark, que buscan provocar incomodidad, desorientación, confusión (1963: 85). Entre ellos está la privación de información o datos que pudieran darle al interrogado alguna sensación de control. Esto se puede ver, por ejemplo, en el hecho de que a los prisioneros no se les informaba de nada: casi nunca sabían dónde estaban, ni se les comunicaba hacia donde los trasladaban. Ni siquiera sabían los nombres de los lugares en lo que los tenían. Dice Luz Arce, estando en Tejas Verdes: "Yo no sabía dónde estaba" (1993: 59); mientras que Roberto Ceballos se pregunta, estando allí mismo: “¿Dónde estaba...? ¿Qué lugar era éste?" (2003: 31). “QQué lugar será?”, se pregunta Manuel Guerrero al ser llevado a una especie de hospital que no logra reconocer (2008: 77). Cuenta Loyola que lo llevan "a algún sitio de Santiago, no sabíamos con exactitud dónde" (2014: 25).

El silencio también es utilizado como modo de infundir temor en los prisioneros durante la tortura. Este método está descrito una vez más en el Manual Ku- 
bark en términos de "amenazas de miedo" (1963: 90-91). El temor a ser dañado, el miedo al dolor posible, futuro, es, según se explica allí, mucho más eficiente para destruir la resistencia del interrogado que infringir daño directamente. Como bien dice Mannoni, "lo desconocido despierta terrores" (1982: 36). La imaginación llena aquel espacio vacío de fantasmas, de demonios, de posibles dolores, etc. De allí que en el Manual se haga ver que si lo que se busca es provocar el desmoronamiento del torturado la amenaza de un posible daño es más efectivo que el daño mismo. Los verdugos utilizan para ello el silencio: no informan, no dicen, ni siquiera amenazan, sino que callan para desencadenar el más profundo terror.

\section{Las víctimas}

Así como el silencio fue una herramienta en manos de los verdugos, un instrumento de tortura y sometimiento, callar también tuvo un sentido para las víctimas. El silencio fue para ellos el instrumento de la victoria. El objetivo primario de la tortura en término concretos es hacer que el detenido hable. Como ha escribo Avelar, un "[c]omponente fundamental de la tortura es la producción de un enunciado en el sujeto torturado, su transformación en portavoz de los enunciados del torturador. La tortura funciona también, entonces, como producción de habla" (2001: 260). Que este es el objetivo primario de la tortura queda en evidencia en los testimonios de los prisioneros. Cozzi, por ejemplo, relata en detalle su diálogo con el fiscal en el Estadio Nacional. Luego de mucho insistir sin éxito, éste grita: “-¡Habla! ¡Habla!” (2000: 69) y más adelante repite: "-¡Ahora vas a hablar! -le daban lumazos en los muslos y las costillas-. ¡Ahora sí que vas a hablar!” (2000: 70). A Nubia Becker, por su parte, el verdugo la amenazaba: "Vas a cantar al tiro no más, huevona, o te vas a ir cortá como la Lummy" (1987: 23).

Ningún detenido quiere hablar, en los testimonios todos relatan su deseo y decisión de no hacerlo. Luego de dos semana de torturas en Villa Grimaldi, Nubia Becker comenta que "[1]o único que ya me importaba era no hablar ni entregar a nadie" (1987: 28). Finalmente logra callar y relata así su triunfo: "No di ninguna información... tuve la certeza que estaban despistados conmigo. Que sólo sabrían algo si se los decía yo misma..." (1987: 36). Durán lo ve claramente cuanto explica que "el silencio y el engaño eran tus mejores amigos, información era lo que no podías dar si querías sobrevivir" (2003: 73). Callar es vencer para el torturado. Hubo, por supuesto, algunos éxitos más parciales como conseguir tan solo un silencio temporal. Los detenidos logran no delatar a nadie por un corto tiempo, al menos el suficiente como para que se tomen las medidas necesarias en vistas de proteger a los cercanos. Luz Arce, por ejemplo, con el objetivo de salvar a su hermano resiste "tres días de tortura para darle el tiempo a que se diera cuenta que yo había caído y limpiara la casa" (1993: 109).

El silencio de los torturados enardece a los interrogadores, a los guardias, a los victimarios, prueba evidente de su impotencia. "El encargado de darme 'la 
bienvenida' está frente a mí. Su voz es muestra clara de que es más bajo que yo. Hace alardes de su valentía a 'chuchada limpia' y patadas en las piernas, molesto sin duda por mi silencio" (Ahumada 2011: 69). Ante la exigencia de hablar, Manuel Guerrero responde: "-No tengo nada que contar". La reacción violenta no demora. "Esperé otro golpe. Llegó y fue más violento. Del pelo a los pies me sobrecogió el dolor. La herida manaba más sangre. -Vos creí que somos aprendices, hijo de puta; si te buscamos fue por algo. Si querís tirarte a choro te vai cortado" (2008: 31). La violencia extrema de la reacción habla de la derrota de los interrogadores ante el silencio de las víctimas. Si no hablan, si no delatan, han vencido, ganaron, porque el triunfo está en callar, en mantener el silencio, aunque ello acarreaba consecuencias terribles para los prisioneros. Sartre había escrito que "callarse no es quedarse mudo, es resistir a hablar, y por eso, hablar todavía" (1958: 17) a lo que Schuffer agrega que callar "es decir, ubicar en el silencio una última libertad humana sobre los límites de la traición" (2016: 121).

\section{SECRETO}

El lugar que ocupa el silencio en la tortura no se agota en su sentido instrumental, sino que se extiende en la forma del secreto abarcando todo el fenómeno. La tortura fue y es hasta el día de hoy en muchos sentidos un secreto. Heller ha definido el secreto como "la privilegización de algunos contenidos cognoscitivos, es la iniciación al conocimiento de algún saber que (...) es comunicado a personas elegidas según determinados criterios" (1987: 327). Existe un grupo restringido de sujetos que son los que acceden a la información privilegiada. Es lo que Goffman ha llamado "secretos internos" que son, según explica el autor, "aquellos que indican la pertenencia del individuo a un grupo y contribuyen a que el grupo se sienta separado y distinto de los individuos que no están 'en el saber'"' (2004: 153).

\section{Autoridades dictatoriales}

En tanto que secreto interno, se constata en el Chile dictatorial la existencia de un determinado grupo que comparte el secreto de la tortura, que está en el saber, como dice Goffman (2004). Forman parte de este grupo, en primer lugar, las autoridades de la dictadura. Ellos negaron sistemática y permanentemente el hecho de que se torturaba en Chile ${ }^{1}$. Estamos aquí ante un silencio oficial. Ejemplos se pueden encontrar sin mayores dificultades. Son bien conocidas las declaraciones que Humberto Gordon, Director de la CNI, diera en diciembre de 1983:

Paz Rojas habla justamente de un silencio profundamente grave, que es aquel que "viene desde el poder total, plagado de engaños, mentiras y manipulaciones habidas durante la dictadura, o mediatizado o transfigurado, donde la verdad integral se dice y al mismo tiempo no se asume, o se deriva a otros poderes del Estado" (2004: 166). 
Pregunta: Según los afectados, esos interrogatorios en los cuarteles de la CNI incluyen desde golpes hasta corriente...

Respuesta: No. La CNI no tortura

Pregunta: Existen innumerables testimonios, general, de que la CNI sí tortura.

Respuesta: Son testimonios y denuncias falsas. Apenas la CNI toma a un detenido aparece un abogado a explotar la situación... No me atrevo a prejuzgar pero le aseguro que no hay nadie que, en conciencia, pueda decir eso.

Pregunta: ¿Lo está diciendo sinceramente general?

Respuesta: Sinceramente. Le advierto que yo mando en la CNI.

(Correa 1983)

De parte de la autoridad dictatorial lo único que hay en lo referente a la tortura es silencio. María José Luque publica un texto que comienza con la siguiente frase: "El carepalismo es un fenómeno que ha tenido su apogeo en los últimos años. Consiste en la capacidad de negar, sin alterarse, situaciones que se registran en el país y que grandes mayorías observan" (1987: 6). La autora acusa a todas las autoridades del gobierno dictatorial de incurrir en esta práctica y alude expresamente al tema de la tortura, haciendo ver que pese a haber denuncias ante los tribunales, a haber ex torturadores confesos, a que hay funcionarios de la CNI procesados por los tribunales, siguen negando su práctica:

Frente a esta realidad recientemente el Ministro Secretario General de Gobierno, Orlando Poblete, declaró “interna y externamente el Gobierno se ha planteado con un rechazo categórico a la tortura y que lo que existe en realidad es un interés de atribuir al Gobierno excesos, y de presentarlo comprometido con actos ilícitos. Es más, el Ministro de Relaciones Exteriores, Ricardo García, firmó la semana pasado en la OEA el Acta de la Convención Interamericana para Prevenir y Sancionar la Tortura". "Chile repudia la aplicación de la tortura", afirmó. El propio general Pinochet declaró en marzo de este año que "las Fuerzas Armadas chilenas nunca han participado en acciones de tortura"(1987: 6).

Esto que Luque ha calificado de "carepalismo" bien podría comprenderse en el marco del llamado "problema de las manos sucias" Walzer (1973) lo bautiza de este modo a partir de la obra de teatro homónima de Sarte. El dilema ha tenido un claro desarrollo hasta nuestros días (Coady 1995; Rynard y Shugarman 2000; López Restrepo 2006; Wijze 2007 y 2018; Meisels 2008; Bellamy R. 2010; Archard 2013), aunque su origen puede rastrearse hasta Maquiavello. La idea es que quien gobierna debe estar dispuesto a "ensuciarse las manos", es decir, que se reconoce la necesidad de los gobernantes, especialmente en situaciones extremas, de realizar acciones moralmente incorrectas, incluso reprobables, con 
el fin de preservar un bien mayor o simplemente evitar grandes males. El ejemplo más discutido, que ya fuera propuesto por Walzer (1973: 167) mismo, es el de la posibilidad de torturar a un terrorista con la intensión de saber la localización de la bomba que ha plantado y salvar con ello a cientos o tal vez miles de personas. Este problema ha adquirido mucha relevancia en el último tiempo y se ha analizado bajo el nombre propuesto por Shue (2005) del "tic-tac de la bomba" (Davis 2005; Miller 2005, 2008 y 2009; Roth y Worden 2005; Sussman 2005; Bagaric y Clarke 2007; Hill 2007; Brecher 2008; Matthews 2008; Steinhoff 2010).

La decisión de torturar por parte de la autoridad es una opción por ensuciarse las manos que debe permanecer en el más absoluto secreto. Ya Maquiavelo exigía que el príncipe debe presentarse antes sus súbditos como inocente y bueno para poder mantener su poder pese a actuar inmoralmente. Contemporáneamente es lo que dice Hollis cuando exige de los políticos que deben "get his hands dirty and wear clean gloves" (1982: 389). En otras palabras, no se debe saber que los líderes políticos se han ensuciado las manos: no se debe saber que han sido las autoridades las que ordenan torturar. La tortura debe ser un secreto, uno de los que Goffman ha calificado de "secreto oscuro". Es decir, aquellos secretos que "tienen su razón de ser en que se trata de hechos concernientes al equipo que este conoce y oculta, y que son incompatibles con la imagen de sí mismo que el equipo se esfuerza por presentar y mantener ante su auditorio" (2004: 152). El régimen dictatorial chileno manejó un discurso salvacionista y refundacional que es incompatible con la tortura indiscriminada. La población no podía ni debía -así como aún no puede ni debe- saber que para salvar y refundar Chile se detuvo ilegalmente a personas, se les interrogó y torturó. No se debía conocer la existencia de estas actividades, pues ello habría enturbiado, ensuciado la imagen que se quería, y aún hoy se quiere proyectar.

El secreto de la tortura, no obstante, también se acerca a lo que el mismo autor caracteriza como "secreto estratégico", es decir, cuando el secreto es funcional a los objetivos que se buscan alcanzar. "Atañen a los propósitos y capacidades del equipo, que este oculta a su auditorio a fin de impedirle que se adapte eficazmente al estado de cosas que el equipo se propone lograr" (Goffman 2004: 153). Si la existencia del hecho de que se torturaba se hubiese hecho pública, si se hubiese reconocido oficialmente, el «enemigo interno» habría tenido la oportunidad de adaptarse eficazmente al estado de las cosas. La oposición hubiera podido implementar estrategias más eficaces de resistencia, tanto a nivel nacional como internacional, logrando que la tortura no cumplieran cabalmente su función.

El silencio y negación de las autoridades dictatoriales respecto de la tortura no se termina con el fin de la dictadura, sino que continúa hasta hoy, pese a los juicios, a las pruebas evidentes, a los informes oficiales, etc. Manuel Contreras señalaba en una entrevista para CNN en 2013 que: "en los cuarteles de la DINA nunca se torturó a nadie... No se utilizaban [las torturas], no estaban ordenadas, ni dispuestas, ni nadie podía hacerlo" (ABC 2013). Su aplicación parece ser 
un secreto de esos que duran para siempre. Los secretos profundos y aquellos estratégicos, que además son profundos, señala expresamente Goffman, son secretos eternos, es decir, el equipo los "trata de mantener para siempre ocultos" (2004: 153). Cuando este tipo de secreto se vuelve "interno" es que los lazos entre los miembros se estrechan y la exigencia de mantenerlos se torna radical.

\section{Perpetradores}

Las autoridades de la dictadura chilena no son los únicos que están en el secreto. También los perpetradores directos, todos los que participan en lo que podría llamarse el «equipo torturador», guardan la más estricta reserva. Ni los fiscales, ni los oficiales, ni los carceleros, ni siquiera los mozos de cuartel o los médicos hablan: ninguno de los que constituyen esa red articulada de sujetos que hacen posible la tortura confiesa, da información, acepta siquiera el hecho. Todos ellos están en el saber y quedan amarrados en el secreto. Los perpetradores forman parte de lo que se conoce como "pacto de silencio». Recuérdese como ejemplo paradigmático el de Osvaldo "Guatón" Romo cuando se le pregunta directamente si torturó y lo niega

Periodista:- Pero, torturaste a muchas.

Romo:- ¡No! Yo no torturé. Torturé, torturar, es lo que dice la gente, torturar, eso que te vuelvo a decir; eso es una fantasía creada por los organismos internacionales.

(Guzmán 2000: 209).

Este pacto de silencio se mantiene hasta nuestros días, aunque, por supuesto, su existencia misma es parte del acuerdo. En 2014, Sergio Muñoz, Presidente de la Corte Suprema en ese momento, declaraba que durante años un grupo grande de militares se ha cuidado de involucrar a otros oficiales en estos delitos de Lesa Humanidad. "Sí eso significa pacto de silencio, bueno, yo creo que lo tienen todas las personas que están imputadas en hechos ilícitos" (Semana 2014). En respuesta, el Comandante en Jefe del Ejército, General Humberto Oviedo negó que existiera un pacto de silencio y dijo que lo que sucede es que algunos militares "en condición de retiro y que, por efecto de su defensa y conforme a la ley que se los permite, pueden entregar o no los testimonios que ellos estimen convenientes" (Semana 2014). Ese mismo año la Presidenta de la República Michelle Bachelet pide expresamente que se rompa el pacto de silencio en las Fuerzas Armadas, solicitud que repetirá al año siguiente cuando un conscripto decide hablar destrabando el emblemático Caso Quemados.

Pese a presentar algunas pequeñas fisuras o grietas, dicho pacto, sin embargo, no se rompe hasta hoy. Los involucrados no están dispuesto a hablar: no quieren o no pueden hacerlo. No es tan solo, siguiendo a Goffman, un pacto que se acepta suscribir, es también uno del que se ordena tomar parte bajo amenaza de muerte. Samuel Vidal, uno de los carabineros que testifica en el caso Masacre del Laja, 
señala en el programa En la Mira de CHV que "nos hicieron hacer un juramento de que no podíamos decirle a nadie esto [de la muerte de los trabajadores]. Había dos civiles y éramos 13 carabineros. Nos dijeron que el que rompía el pacto de silencio iba a tener problemas la familia o uno" (2015).

\section{Colaboradores y aprovechados}

Hay otro grupo que participa del secreto de la tortura. Se trata de terceras personas que no fueron autoridades, ni ejecutores directos, ni uniformados, ni miembros de los Servicios Secretos, pero que accedieron a la información y guardaron silencio. Estamos aquí ante sujetos que conociendo el secreto no lo revelan, pues les ha sido "depositado" como explica Goffman (2004). Se trata de aquellos a los que, pese a no ser parte integrante del grupo de los que están en el secreto, este les ha sido confiado y se ven obligados a conservarlo, dada su relación con el grupo. En este lugar está, por ejemplo, aquella parte de la sociedad civil que fue partidaria de la dictadura y que colaboró con ella. A ellos se les confía el secreto de la tortura, y callan por lealtad y convicción.

Podríamos extender esta figura a terceras personas que, aunque no les ha sido revelado directamente, conocen el secreto, se les permite que lo conozcan y no lo hacen público: callan. Dicha decisión, sin embargo, no surge de una obligación, ni de la relación que tengan con el equipo, sino más bien de otras motivaciones como puede ser, por ejemplo, la existencia de una ganancia concreta. Para algunos existió un beneficio en el respetar el secreto, mayor que el beneficio que podría haber tenido el revelarlo. A raíz de este cálculo deciden no solo respetarlo, sino incluso defenderlo. En este sentido hace ver Vidal que "[e]l Informe Rettig da cuenta, por ejemplo, de que la crema de la intelectualidad de la Universidad Católica que apoyó al régimen militar supo tempranamente de las atrocidades cometidas por las Fuerzas Armadas y prefirió no intervenir decisivamente para conservar su influencia política" (2000: 13). Se conserva un secreto, pues se han obtenido ganancias por los logros del equipo: dicha ganancia los hace cómplices y, por lo tanto, se obligan a callar. Las ganancias, por supuesto fueron de diferentes tipo y no solo política, sino que también económica, sociales, incluso personales.

\section{Sociedad}

Como sea, en definitiva son pocos los que están en el secreto, sin embargo, esto no quiere decir que de la tortura no se supiera, ni se sepa. La tortura en Chile fue y es un secreto público². Como han escrito López y Otero, ella "[h]ará su vida oculta, pero no tanto como para no saber de ella" (1989: 53). Por lo tanto, la existencia pública de la tortura, en términos de Egaña, es la de un "murmullo, 
rumor, huella" de un "hecho macabro que se intenta encerrar y cubrir" (2005: 65). Aunque el discurso oficial niegue su existencia, permite que alguna información se filtre, que se escurra hacia el público. Pese a no haber una versión oficial que afirme la existencia de estas práctica, era sabido, es sabido que se torturaba. "La gracia del secreto es que está en el límite que divide la realidad con la fantasía, y es por eso que el manto que cubre a la tortura es eternamente imperfecto; es más, gran parte de su eficiencia radica en ello" (2005: 68). Egaña advierte aquí algo que en principio podría parecer sorprendente: que la eficiencia de la tortura radicaría justamente en esta situación ambigua de ser un secreto a voces.

Las filtraciones del secreto de la tortura no fueron, por lo tanto, producto de un error o un descuido, sino que eran y son de orden instrumental, incluso estratégico. La razón de ello, como sugiere Egaña (2005), podría hallarse en que la condición de ser una información filtrada, pero no del todo corroborada, aunque bastante cierta, contribuye a que la tortura cumpla mejor sus objetivos. Los que, como es bien sabido, son múltiples. Sin ir más lejos, Briceño enumera once objetivos diferentes (1998: 30). Entre aquellos cuya consecución se facilita con estas filtraciones está sin duda el de proyectar el terror sobre la población. Tito Tricot hacer ver "que el uso de la tortura no es considerado un medio ideal para obtener información, aunque sí de relativa eficacia en la proyección del terror" (1990: 4). Aterrorizar e intimidar a la población, al grupo disidente y a todo quien pudiera tener objeciones, parece ser una de las principales finalidades; la amenaza de tortura debe abandonar los centros, los cuarteles, las cárceles clandestinas y esparcirse por todo el territorio aterrando a los habitantes. La idea es, en palabras de Egaña, "instaurar un estado generalizado de terror" (2005: $60)$, y para que ello ocurra la tortura "no puede eliminar todas las marcas de su existencia (...) dejar pequeñas huellas es parte del montaje, las suficientes para alejarla del olvido, pero demasiado pocas para transformarla en una certeza generalizada" (2005: 68-69). Dichas huellas son justamente los testimonios de los que fueron torturados: ellos dispersan el rumor y el terror ${ }^{3}$.

Muchos -tal vez casi todos- supieron de la tortura, pero callaron y callan aún por temor. El texto de Politzer Miedo en Chile abre con la siguiente frase: "Chile tuvo y tiene miedo. Un miedo que nos hace vivir a medias, reprimidos y sofocados" (1985: 9). La dictadura, explica la autora en su prólogo, es algo cotidiano que lo impregna todo, hasta lo más íntimo y, por lo tanto, todos - incluso los indiferentes y los que la apoyan- son sus víctimas. La razón es clara, dice: "también ellos están envueltos en las redes de un sistema que determina lo que hacemos y no hacemos, lo que pensamos, lo que creamos, lo que soñamos y lo que callamos" (1985: 9). En este sentido es que López y Otero han sostenido la tesis de que la tortura es una forma de pedagogía: una "pedagogía del terror" (1989: 77). Se trata, según estos autores, de una pedagogía muy eficiente, aunque nada

Hablando del sobreviviente, Longoni hace ver justamente que "su testimonio actúa como involuntario dispositivo dispersor del terror fuera del campo, y se explique su sobrevivencia como parte de la lógica de la represión que habría dejado sobrevivientes funcionales a dar testimonio sobre la eficacia del castigo" (2007: 22). 
respetuosa (1989: 78). Como no se puede torturar/educar directamente a toda la población, es necesario difundir su existencia y sus efectos formativos. Señalan además que "[e]l uso dosificado y medido de la información que habla a otros sobre estos hechos, basta para hacer extensiva la formación a personas que no han recibido su propia lección. El efecto deseado por la tortura se generaliza por medio del miedo" (1989: 78).

La sumisión, la complacencia, el consentimiento, la aceptación, son los efectos pedagógicos del terror que se expande por el cuerpo social. Mediante las filtraciones, a través de la administración de cierta información, la dictadura depositó el secreto de la tortura en toda la sociedad y con ello nos hizo cómplices. Quienes sabían de la tortura estaban, en definitiva, en el secreto y su silencio fue un silencio cómplice. Incluso las víctimas mismas de la tortura se vuelven cómplices con su silencio. Agüero lo escribe en su conocida carta: "He caído en cuenta que mi silencio termina, en verdad, por hacerse cómplice del engaño al que este individuo [Emilio Meneses] somete a diario a todos quienes le rodean" (El Mostrador 2001).

\section{INDECIBILIDAD}

El silencio de Agüero no es excepcional, pues lo comparte con muchas de las víctimas de tortura, a las cuales el silencio se les aparece imposible de superar, pues simplemente no pueden hablar. Se trata de un silencio inevitable, de la imposibilidad de hablar de lo ocurrido o, como se ha expresado también, la "[i] ndecibilidad de la experiencia límite" (Jelin 2006). Esta indecibilidad, como ha visto Jelin, se manifiesta al menos de dos formas. Por una parte, están aquellos que simplemente no pueden hablar en absoluto de lo experimentado $y$, por otra parte, están aquellos que hablan, incluso obsesivamente, de lo vivido, pero que no pueden evitar "sentirse siempre traicionados por la falta de palabras adecuadas o por la insuficiencia de los vehículos para trasmitir sus vivencias" (Jelin 2006: 66). La gran mayoría de quienes estuvieron prisioneros y fueron torturados están en el primer caso: callan, renuncian a hablar, desisten de intentar siquiera poner en palabras lo que les ha ocurrido. La mayoría de ellos lo hacen simplemente porque no les parece posible hacerlo. Hay otros, los menos, que están en el segundo caso: escriben, hablan, dicen, denuncian, etc. pero sufren de la angustia de no poder dar nunca con la expresión correcta para referirse a lo ocurrido.

En ambos casos se trata, como se puede observar, de una falta de palabras, de una ausencia de expresión. Ello puede deberse a que simplemente no existen las palabras adecuadas para expresar la experiencia: el orden simbólico disponible no alcanza y los recursos retóricos no dan para poder dar cuenta de ella. Vuskovic (2006) citando a Helmuth Frenz escribe: "[e]l lenguaje humano no es capaz de expresar lo que es la tortura" (2006: 47). Luego agrega que "el principio epistemológico es: la experiencia personal es fundante, pero es in- 
decible, de ella no se puede hablar" (2006: 47). Paz Rojas escribe respecto de las víctimas de tortura:

Esta experiencia deja a las víctimas sin palabras para comunicar lo vivido. No existe lenguaje, lo que predomina en lo inmediato y más tarde, en el recuerdo, son el estupor, la perplejidad y, por ende, el silencio. No existe tampoco una semántica, un código que denomine la conducta del victimario: destrucción, negación, violación, amenaza de muerte, desaparecimientos, perversión y desgarro, que son ocultados por la negación y el silencio. (2004: 164)

El silencio, lo inenarrable de la experiencia, sin embargo, no se debe tan solo a una falta de palabras, a la ausencia de una retórica que pudiera aprehender lo vivido. No se trataría únicamente de un problema categorial que se soluciona creando, inventado o, en su defecto, tomando prestadas formas de expresión adecuadas para describir la experiencia. El silencio, lo inenarrable o la falta misma de categorías reconoce una causa anterior: lo inverosímil de la experiencia misma. Por tratarse de una situación tan incomprensible, simplemente no parece posible relatarla. Escribe Luz Arce que "[n]o podía expresar lo vivido, algo dentro se rebelaba a aceptar que era verdad toda esa violencia, ese ser nada, ese no tener ningún derecho. Yo quería creer que no era cierto, que en algún momento había enloquecido, que no era verdad" (1993: 371). Ahumada parece expresar la misma idea cuando señala: "Por años guarde silencio.... Y es que hubo momentos en que me sentí como enloquecido, al margen de mis fuerzas, sin lograr que todo encajara" (2011: 102). Vuskovic lo explica claramente: "La dificultad del lenguaje para presentar la tortura viene del hecho que el sujeto que la sufre se encuentra siempre frente a un misterio" (2006: 49)

Más allá de la imposibilidad, de la falta de categorías, del misterio que la tortura representa, hay también razones afectivas por las cuales se calla. Los ex prisioneros no hablan, en gran medida, por miedo. Junto con la foto y la firma, el otro trámite infaltable antes de salir de la prisión era la amenaza. La orden era mantenerse fuera de la política, de no hacerlo la consecuencia sería volver a prisión y, eventualmente, la muerte. En la mayoría de los casos, el silencio era además una exigencia expresa y la amenaza seguía siendo la misma. Es lo que le dicen, por ejemplo, a Ahumada cuando sale: "Tú te vas libre, pero mucho cuidado con contar lo que aquí ha sucedido. No recuerdas nada ni viste nada. Que te quede claro, porque en cualquier momento puedes volver aquí si no cumples con esto. Serás vigilado y pobre de ti que nos volvamos a encontrar" (2011: 115). Al salir de la prisión todos declaran sentir que son vigilados. Quijada llega a sostener que tenía la sensación de no haber salido nunca del campo: “Comprendí después que no estaba libre. Había un cerco que salía de los centros de detención y se prolongaba afuera rodeando la ciudad. Podía verse en las calles alrededor de cada casa, circulando a las personas, con sus púas bien dispuestas" (1990: 173). No podía hablar con nadie, cualquiera podía ser un agente o un soplón. "Si. Estaba libre. Libre para ver y oír y hasta para caminar en la 
ciudad ocupada. Pero casi no podía hablar... Era, ahora, un hombre sellado, mudo" (Quijada 1990: 173). La única alternativa era la seguridad del silencio.

Los ex detenidos no callan solo por miedo a las consecuencias, sino que también por temor a no poder seguir adelante con sus vidas. Quien era liberado enfrentaba una serie de amenazas que atentaban contra su presente y su futuro. Las había de orden práctico que eran muy concretas: los ex prisioneros no encontraban trabajo, no contaban con redes de apoyo ${ }^{4}$. Había una sospecha que recaía sobre todo aquel que estuvo detenido, una sospecha que cerraba puertas. Por una parte estaba la sospecha de traición, como bien ha hecho ver Longoni: "Los que atravesaron por el espacio y el tiempo suspendidos del campo clandestino y retornaron a este mundo generan desconcierto, incomodidad, sospechas en los otros. Sobre ellos pesa la culpa de estar vivos, la suposición de que para vivir hicieron un pacto con el Mal, cuando miles a su alrededor morían" (2007: 29). Por otra parte, existía la sospecha de delincuencia. "[E]l relato autobiográfico de la tortura no es legítimo, pues éste pertenece al estigma del delincuente" (Egaña 2005:66). Hernán Vidal señala que la dictadura pretende:

convencernos de que la tortura no es un asalto contra toda una colectividad nacional sino el castigo legítimo de «unos pocos» que transgredieron criminalmente normas fundamentales de buen gobierno. Por tanto [...] el trauma no debe ser expuesto a la mirada pública sino escondido con vergüenza en el espacio de lo íntimo y de lo privado. (2000: 9)

La experiencia de prisión y la tortura se guarda, se esconde entre las paredes de hogar, no debe salir de allí, no puede ser expuesta al ojo acusador: se calla.

Falta de palabras, incapacidad de hablar, temor, son razones que mueven a los que fueron torturados a callar. Es posible entender este silencio, no obstante, también como la reacción frente a un otro que no quiere escuchar. Jelin ha observado que "[1]a necesidad de contar puede caer en el silencio y en la imposibilidad de hablar por la inexistencia de oídos abiertos dispuestos a escuchar. Y entonces hay que callar, silenciar, guardar o intentar olvidar" (2006: 66). La falta de oídos puede tener muchas causas, entre ellas está, en primer lugar, la negación.

[T]ambién el silencio viene de la sociedad que margina y niega la presencia de los sobrevivientes, posiblemente por no querer reconocer la existencia de la tortura, por negarse a creer que ella realmente existió en todo ese tiempo, pues conocerla y aceptarla significaría constatar sin

\footnotetext{
“¡Incrédulo! Iluso, soñador que vive fuera de la realidad, pues me encontraría con cantidad de amigos temerosos de saludarme, con puertas cerradas casi en las narices, con buenas oportunidades, pero..., y ese 'pero' era siempre la barrera que se interponía. -Fuiste prisionero político y no nos podemos comprometer, perdón, pero tú sabes. Y bien que lo supe al ver pasar y pasar el tiempo sin poder encontrar trabajo, sin dinero para las mínimas necesidades, con sólo promesas, trámites y más trámites. - Mira, todo va bien, tienes el trabajo asegurado, vuelve la próxima semana. Y esa próxima semana nunca llegaba, hasta que al final salía la verdad: - Por mí no hay problemas, pero mi socio tiene miedo y tú sabes, la situación" (del Valle 1997: 150).
} 
ambigüedades la presencia del mal radical entre nosotros. (Rojas 2004: 165-166).

\section{OBLITERACIÓN}

La falta de oídos puede tener su origen también en una decisión política de no escuchar o, dicho de otra forma, la estrategia de escuchar para dejar de escuchar. El objetivo sería dejar el pasado atrás. Esto ha sido en Chile parte esencial del discurso transicional: no seguir escarbando en el dolor pasado, superar lo que nos divide, mirar al futuro. Como decía Patricio Aylwin al presentar el informe Rettig: "Muchos compatriotas piensan que es tiempo de poner 'punto final' a este asunto. Por el bien de Chile, debemos mirar hacia el futuro que nos une más que al pasado que nos separa, insistir en ello sería desgastar nuestros esfuerzos en escudriñar heridas que son irremediables". Luego agrega enfáticamente: “Quién podría no compartir estos anhelos?". Las iniciativas que se han llevado a cabo desde el Estado en el ámbito de la investigación de las violación a los derechos humanos durante la dictadura pueden ser interpretadas como un intento por poner ese "punto final" a este asunto, de clausurarlo de una vez por todas.

Desde el término de la dictadura se han impulsado una serie de iniciativas oficiales en vista de develar las atrocidades cometidas: Comisión de Verdad y Reconciliación ${ }^{5}$, Mesa de diálogo sobre Derechos Humanos ${ }^{6}$ y Comisión Nacional sobre Prisión Política y Tortura ${ }^{7}$. Ellas tuvieron como objetivo investigar lo acontecido. En el caso de la tortura, es la última de las comisiones la más relevante, puesto que su tarea fue, según se establece en su acta de creación:

determinar, de acuerdo a los antecedentes que se presenten, quiénes son las personas que sufrieron privación de libertad y torturas por razones políticas, por actos de agentes del Estado o de personas a su servicio, en el período comprendido entre el 11 de septiembre de 1973 y el 10 de marzo de 1990. (Art. Nº1, Decreto Supremo No 1.040).

Todas estas iniciativas oficiales tuvieron desde su constitución evidentes limitaciones. Quizás la más clara, pero no la única, sea la exclusión de ciertos asuntos. En el caso de la Comisión Valech se dejan fuera todas la privaciones de libertad y tortura que no fueran perpetradas por "razones políticas", así como también

5 En 1990, durante el gobierno de Patricio Aylwin, se implementó esta iniciativa cuyo informe lleva el apellido de quien la dirigiera: Rettig. La comisión trabajó durante nueve meses y presentó sus resultado al presidente el 8 de febrero de 1991.

6 Durante el gobierno de Eduardo Frei Ruiz-Tagle se instauró esta iniciativa que funcionó entre el 21 de agosto de 1999 y el 13 de junio de 2000, ya en el gobierno de Lagos. Como resultado de los acuerdos alcanzados, en enero de 2001, las Fuerzas Armadas y de Orden entregaron un listado señalando lo que habría sido el destino final de 200 víctimas, entre ellas 180 identificadas y 20 N.N.

7 En el gobierno de Ricardo Lagos se creó esta comisión cuyo trabajo se plasmó en el llamado Informe Valech. Dicho informe tiene dos partes: una publicada en 2004 y otra en 2011. 
todas aquellas que terminaron con la muerte de la víctima, pues ese habría sido el tema de la Comisión Rettig ${ }^{8}$. Otro ámbito de exclusión es lo relativo a las responsabilidades. Es a raíz de ello que se deja fuera del conocimiento público el nombre de los perpetradores. Finalmente, existen sin duda asuntos metodológicos que implican limitaciones. La misma Comisión Valech constata, por ejemplo, la falta de registros de lo ocurrido durante 1973 que es justamente el período en donde hubo más casos (2004: 72). Por lo demás, su accionar estuvo siempre limitado a la recepción de los testimonios que las víctimas estuvieran dispuestas a dar voluntariamente ${ }^{9}$.

En la práctica es imposible que estas iniciativas oficiales puedan dar cuenta de la verdad completa de lo ocurrido. Lo que develan los informes de estas comisiones es tan solo una porción de lo acontecido. Una gran parte de lo que fue la violación de los derechos humanos durante la dictadura no aparece en estos documentos oficiales: queda abandonada en el silencio. El listado de personas víctimas de prisión política que la Comisión Valech "calificó" fue de 27.255 (2004: 73). De ellos, cerca de un 94\% habrían sido torturados (2004: 74). Este número está muy lejos de ser el total de víctimas de prisión y tortura que hubo en Chile durante la dictadura. Los comisionados reconocen expresamente esta realidad. "La Comisión está consciente que, pese al elevado número de víctimas y casos de detenciones y torturas reconocidos, ellos no constituyen la totalidad de personas que sufrieron prisión política y tortura durante el régimen militar" (2004: 75).

Dado este reconocimiento sorprenden los dichos del presidente al presentar el informe. Ricardo Lagos señala en su discurso que el tema de la prisión política y la tortura "estuvo cubierto durante mucho tiempo por un espeso e insano silencio. Eso tenía que terminar, y ha terminado" (2004: 6). El silencio es un tema central del discurso. Lagos lo denuncia y sostiene que con el informe se ha acabado: "[s]e terminó el silencio, se desterró el olvido" (2004: 8). Según el presidente el proceso ha sido doloroso, pero ya se hizo, está terminado. En sus palabras, el Informe "re-construye -31 años después- un cuadro completo de la tremenda abyección que vivió nuestra patria" (2004: 5). Cierra diciendo que "[c]on el reconocimiento a las víctimas de prisión política y tortura completamos un capítulo por el cual teníamos que pasar" (2004: 10). Se enfatiza la idea de la completitud.

Los comisionados reconocen los límites de sus resultados, pero el presidente los presenta como si ello fuera un "cuadro completo" de lo acontecido, como si

8 Como señala Daniela Cuadros, la Comisión Rettig también tuvo claras limitaciones, pues “deja de lado los casos mucho más numerosos de los presos políticos, de las víctimas de tortura, de los exiliados, de los exonerados políticos, etc." (2008: 71). Esto lleva a concluir, como dice Camacho, que "Por el conjunto de aspectos que no fueron abordados por la comisión se puede constatar que se trataba de una verdad a medias, pues faltaban por analizar y relatar muchos otras características que la represión política tuvo en Chile" (2004: 10.060).

9 “La Comisión tiene la convicción de que no concurrió a prestar testimonio todo el universo de personas afectadas por violaciones a sus derechos humanos bajo la forma de prisión o tortura por distintas razones" (2004: 72). 
todo hubiera salido a la luz. Hay un contraste evidente que no puede atribuirse al desconocimiento por parte de Lagos acerca de lo realmente logrado por la comisión Valech. Lo que parece estar detrás del discurso es más bien el interés de que el Informe sirva como "punto final" al tema de la prisión y la tortura. La comisión consiguió develar una parte de lo acontecido durante la dictadura, pero en tanto que se presentan sus resultados como la verdad completa, se ha provoca un efecto paradójico: ella contribuye en definitiva a mantener el secreto y el silencio. El lugar en que el presidente sitúa los hallazgos de la Comisión Valech impide que se siga investigando, que se continúe con la búsqueda de la verdad.

Esta intención de poner un "punto final" al tema se refuerza cuando se decreta la supresión de publicidad de los archivos. En el caso de la Comisión Valech I, los archivos pueden ser desclasificados tan solo después de 50 años de su publicación, lo que incluye al Poder Judicial ${ }^{10}$. Los antecedentes recopilados por las comisiones Rettig, Corporación Nacional de Reparación y Conciliación y Comisión Valech II, por su parte, están sujetos a reserva y solo pueden acceder a ellos los Tribunales de Justicia. La intención ha sido, sin duda, que no se siga indagando, investigando, que se deje el tema atrás: que el punto final se respete, que de una vez por todas reine el silencio.

\section{CONCLUSIÓN}

Se decía al comienzo del texto que el silencio tuvo y tiene un papel central en el fenómeno de la tortura en Chile. Esto se puede corroborar, primero en el hecho de que las autoridades dictatoriales callan sobre su ocurrencia; niegan sistemáticamente su ocurrencia. Del mismo modo, se observaba que tanto los perpetradores directos, como también todos lo que están en el "pacto de silencio" guardan el más cerrado de los silencio. La tortura fue y es hasta el día de hoy un secreto compartido por muchos. Un secreto que se filtra a la sociedad en una dosis necesaria para que cumpla la función pedagógica de aterrorizar. El silencio tiene también, como se ha visto, un sentido instrumental en la tortura, en tanto que el interrogador lo usa cuando está ejerciendo su labor con el objeto de extremar el terror. También es una herramienta en manos de quien es torturado en tanto que el silencio es una victoria: callar, no delatar es haber triunfado. El sobreviviente también guarda silencio en tanto que no consigue articular un relato sobre lo vivido. En definitiva guarda silencio todo un país aterrorizado ante la amenaza de ser torturado. Finalmente las autoridades democráticas y transicionales buscan poner un punto final a la investigación sobre el pasado en tanto que decretar agotado el tema, perpetuando así el silencio. El silencio,

10 Ricardo Lagos señala al presentar los resultados de la Comisión Nacional sobre Prisión Política y Tortura: "Quiero agradecer finalmente a todas las chilenas y a todos los chilenos que prestaron testimonio y estuvieron dispuestos a revivir su sufrimiento por el bien de Chile. Tal como ellos lo pidieron, sus testimonios serán confidenciales y, por tanto, nadie tendrá acceso a ellos durante los próximos 50 años" (2004: 10). 
como se ha podido observar en el caso chileno, no es tan solo un elemento más del fenómeno de la tortura, sino que lo atraviesa por completo tomando múltiples y diferentes modulaciones, convirtiéndose en un componente esencial de su práctica. Dicho de otro modo, no hay tortura sin silencio.

\section{REFERENCIAS}

ABC. 2013, 10 de septiembre. "Exjefe de la DINA chilena niega torturas y desapariciones en dictadura." Recuperado el 12 de agosto de 2017 de http:/ / www.abc.com.py/internacionales/exjefe-de-la-dina-chilena-niega-torturas-y-desapariciones-en-dictadura-616417.html

Aguilera, Juana. 2016, 2 agosto. “Tortura, impunidad y resistencia." Recuperado el 15 de agosto de 2017 de https: / / rufianrevista.org/tortura-impunidad-y-resistencia /

Ahumada, L. Manuel. 2011. Testimonio: Cerro Chena- un campo de prisioneros. Santiago de Chile: Leonardo Sepúlveda Producciones Gráficas.

Álvarez Cancino, Valentina y Victoria Vega Barría. 2014. La violencia sexual sobre los cuerpos de las mujeres como método de tortura durante la dictadura militar chilena (1973-1990): un examen filosófico con una perspectiva de género. Tesis de licenciatura no publicada, Usach, Santiago de Chile.

Andueza Kovacevic, Diego. 2017. "La animalización como mecanismo de deshumanización en la dictadura militar chilena (1973-1990)." Revista latinoamericana de estudios críticos animales I(IV): 4-1.

Archard, David. 2013. "Dirty Hands and the Complicity of the Democratic Public." Ethical Theory and Moral Practice 16: 777-790.

Arce, Luz. 1993. El Infierno. Santiago de Chile: Editorial Planeta

Avelar, Idelber. 2001. "Five Theses on Torture." Journal of Latin American Cultural Studies 10(3): 253-271.

Bagaric, Mirko y Clarke, Julie. 2007. Torture: When the Unthinkable is Permissible. Albany: State University of New York Press.

Becker, Nubia (Carmen Rojas). 1987. Recuerdos de una mirista. Santiago de Chile: Ediciones del Taller.

Bellamy, Richard. 2010. "Dirty hands and clean gloves: liberal ideals and real politics." European Journal if Political Theory 9(4): 412-430.

Brecher, Bob. 2008. Torture and the Ticking Bomb. Oxford: Blackwell.

Briceño, Lesley. 1998. "Tortura y torturadores." Encuentro NXXI: 28-36.

Bulo, Valentina. 2013. “Tábula rasa de los cuerpos." La Cañada. Revista del pensamiento filosófico chileno 4: 206-214.

Calveiro, Pilar. 2008. "La verdad de la tortura en las democracias." Revista Venezolana de Economía y Ciencias Sociales Vol 14 N²: 75-94

Camacho Padilla, Fernando. 2004. “Una Memoria Consensuada: El Informe Rettig." Ponencia presentada en el V Congreso Chileno de Antropología del Colegio de Antropólogos de Chile, San Felipe.

Carrasco, Rolando. 1991. Prigué. Santiago de Chile: Ediciones Aquí y Ahora.

Ceballos Cornejo, Roberto Mario. 2003. Siete hombres junto al río. Santiago de Chile: Tiempo Nuevo.

Central Intelligence Agency (CIA). 1963. KUBARK Counterintelligence Interrogation.

Coady, Cecil Anthony John. 1995. "La política y el problema de las manos sucias." En Compendio de ética, editado por Peter Singer. Madrid: Alianza Editorial, 507-519.

Comisión Nacional de Verdad y Reconciliación. 1991. Informe Rettig: Informe de la Comisión Nacional de Verdad y Reconciliación. Santiago de Chile: La Nación - Ediciones del Ornitorrinco.

Comisión Nacional sobre Prisión Política y Tortura. 2004. Informe Valech: Informe de la Comisión Nacional sobre Prisión Política y Tortura. Santiago de Chile: Ministerio del Interior. 
Comisión Nacional Contra la Tortura. 1984. Así se tortura en Chile. Recuperado el 20 de agosto de 2017 de http:/ / www.bibliotecamuseodelamemoria.cl/gsdl/collect/textosym/ tmp/00000030000017000002.html

Correa, Raquel. 1983, 4 de diciembre. "Entrevista al General Humberto Gordon, director de la CNI". En El Mercurio.

Cozzi Figueroa, Adolfo. 2000. Estadio Nacional. Santiago de Chile: Sudamericana.

Cuadros, Daniela. 2008. "La Comisión Rettig o la fábrica de un relato «consensuado» sobre los crímenes de Estado en Chile. Actores y controversias". En Derechos Humanos en América Latina. Mundialización y circulación internacional del conocimiento experto jurídico, editado por Ángela Santamaría y Virginia Vecchioli. Buenos Aires: CEPI-Universidad de Rosario, 63-84.

Davis, Michael. 2005. "The Moral Justification of Torture and other Cruel, Inhuman, or Degrading Treatment." International Journal of Applied Philosophy 19(2): 161-178.

Del Valle, Juan. 1997. Campos de concentración, Chile 1973-1976. Santiago de Chile: Mosquito Ediciones.

Durán, Claudio. 2003. Autobiografía de un ex-jugador de ajedrez. Santiago de Chile: Lom.

Egaña, Rafael. 2005. Narraciones de la tortura. Su representación en tres textos dramáticos. Tesis para optar al título de Antropología Social, Universidad de Chile, Santiago. Recuperado de http:/ / repositorio.uchile.cl/handle/2250/106445

El Mostrador. 2001, 27 de marzo. "La carta de Felipe Agüero en la que denuncia a su torturador".

En la Mira, 2015, 19 de agosto. "Masacre del laja". Recuperado de https://www.youtube. com/watch?time_continue $=119 \& v=y$ T9W70BFILQ\&feature $=e m b \_l o g o$

Forner, Juan Pablo. 1990. Discurso sobre la tortura. Valparaíso: Edeval.

Galiano, José. 2001. "El delito de tortura ante el Derecho Internacional y la Ley Chilena." Primer Informe de la Comisión Ética contra la Tortura. Santiago de Chile: Comisión Ética contra la Tortura.

García Villegas, René. 1990. "La Tortura, el daño y la reparación". En Tortura: Aspectos médicos, psicológicos y sociales. Prevención y tratamiento. Santiago de Chile: Equipo de Salud Mental-DITT del Comité de Defensa de los Derechos del Pueblo (Codepu).

Goffman, Erving. 2004. La presentación de la persona en la vida cotidiana. Buenos Aires-Madrid: Amorrortu Editores.

Guerrero Antequera, Manuel. 1999. La tortura: poder y saber resistencial. Santiago de Chile: Universidad Arcis.

Guerrero Ceballos, Manuel. 2008. Desde el túnel: diario de vida de un detenido desaparecido. Santiago de Chile: Lom.

Guzmán, Nancy. 2000. Romo: Confesiones de un torturador. Santiago de Chile: Editorial Planeta. Heller, Agnes. 1987. Sociología de la vida cotidiana. España: Península.

Hevia, Evelyn. 2014. Memorias subterráneas en el Chile actual: el lugar de la traición en las memorias de sobrevivientes de Villa Grimaldi. Tesis para optar al grado de magister en Historia, Universidad de Chile, Santiago. Recuperado de http://repositorio.uchile.cl/ handle/2250/131417

Hill, Daniel. 2007. "Ticking Bombs, Torture and the Analogy with Self-defence." American Philosophical Quarterly 44(4): 395-404.

Hollis, Martin. 1982. "Dirty hands." British Journal of Political Science 12(4): 385-398.

Jelin, Elisabeth. 2006. "La narrativa personal de lo 'invisible'". En Historia, Memoria y Fuentes orales, editado por Vera Carnovale, Federico Lorenz y Roberto Pittaluga. Buenos Aires: Cedinci, 63-79.

Lagos, Ricardo. 2004. “Prólogo. Reflexiones propuestas por S.E. el Presidente de la República, Ricardo Lagos Escobar". Informe Valech: Informe de la Comisión Nacional sobre Prisión Política y Tortura. Santiago de Chile: Ministerio del Interior.

Longoni, Ana. 2007. Traiciones. Las figuras del traidor en los relatos acerca de los sobrevivientes de la represión. Bueno Aires: Editorial Norma.

López, Ricardo y Edison Otero. 1989. Pedagogía del terror: un ensayo sobre la tortura. Santiago de Chile: Atena. 
López Restrepo, Andrés. 2006. "El problema de las manos sucias". Ciencia Política 1(2): 151167.

Loveman, Brian y Lira, Elizabeth. 2004. "Marco histórico: Terrorismo de Estado y tortura en Chile". En De la tortura no se habla: Agüero Versus Meneses, editado por Patricia Verdugo. Santiago de Chile: Catalonia.

Loyola Muñoz, Daniel. 2014. Vuelvo para vivir: Testimonio de un sobreviviente. Santiago de Chile: Ocho libros Editores.

Lyons, Lewis. 2005. Historia de la tortura: de los albores de la humanidad a nuestros días. México: Diana.

Luque, María José. 1987. "Sicopolítica: la eterna historia oficial” Análisis 10(195).

Madariaga, Carlos. 1989. “Tortura, Persona y Sociedad." Revista Reflexión N¹04.

Mannoni, Pierre. 1982. El Miedo. Ciudad de México: FCE.

Martínez, Nicolás. 2017. "Sujetos e imaginarios sociales en el discurso de sobrevivientes de la tortura en la Dictadura Cívico-Militar en Chile." Discurso y Sociedad 11(3): 485-511.

Matthews, Richard. 2008. The Absolute Violation: Why Torture Must be Prohibited. Montreal: McGill-Queen's University Press.

Meisels, Tamar. 2008. "Torture and the Problem of Dirty Hands". Canadian Journal of Law and Jurisprudence 21(1): 149-173.

Mellor, Alec. 1949. La torture: son histoire, son abolition, sa réapparition au XXème siècle. Paris: Les Horizons Littéraires.

Miller, Seumas. 2005. “Is Torture Ever Morally Justified?" International Journal of Applied Philosophy 19(2): 179-192.

Miller, Seumas. 2008. "Torture". En Stanford encyclopedia of philosophy, editado por Esward Zalta.

Miller, Seumas 2009. Terrorism and Counter-terrorism: Ethics and Liberal Democracy. Oxford: Blackwell.

Moreno, Eleonor. 2008. Resistencia en la tortura. Análisis del discurso de ex prisioneros(as) politicos(as) de la dictadura militar chilena (1973-1990). Tesis para optar al título de Psicóloga, Universidad de Chile, Santiago. Recuperado el 12 de noviembre de 2017 de http:// repositorio.uchile.cl/bitstream/handle/2250/106077/moreno_e.pdf?sequence=3\&isAllowed $=\mathrm{y}$

Moya, Laura (comp.). 2005. Tortura en poblaciones del gran Santiago (1973-1990). Santiago de Chile: Corporación José Domingo Cañas.

Navarro, Ariel. 2015. Médicos torturadores: participación y uso del conocimiento médico en el aparato represivo del estado, 1973-1990. Tesis para optar al grado de Licenciado en Historia, Pontificia Universidad Católica de Valparaíso, Chile.

Neumann, Elisa y Consuelo Macchiavello. 1990 “Incomunicación prolongada: otra forma de tortura. Repercusión psicológica en el individuo". En Tortura: Aspectos médicos, psicológicos y sociales. Prevención y tratamiento. Santiago de Chile: Equipo de Salud Mental-DITT del Comité de Defensa de los Derechos del Pueblo (Codepu).

Osorio, Valeria. 2012. "Tortura en la dictadura chilena: la segregación de la anesthesia." Sociedad \& Equidad 3: 239-248.

Palacios Prado, Rafael. 2011. Tortura y terrorismo: acerca de la relativización de la prohibición internacional de la tortura en casos de terrorismo global. Tesis para optar al grado de Licenciado en Ciencias Jurídicas y Sociales, Universidad de Chile, Santiago.

Pesutic, Sergio. 1996. "Los profesionales de la salud y la tortura". En Persona, Estado, Poder: Estudio sobre Salud Mental. Chile 1990-1995. Vol. II, editado por Paz Rojas. Santiago de Chile: Codepu.

Politzer, Patricia. 1985. El Miedo en Chile. Santiago de Chile: Cesog Ediciones.

Publimetro. 2015, 2 de agosto. "El otro pacto de silencio que dejó al descubierto En la Mira." Recuperado el 23 de agosto de 2017 de https://www.publimetro.cl/cl/nacional/2015/08/20/pacto-silencio-que-dejo-descubierto-mira.html

Quijada, Aníbal. 1990. Cerco de púas. Santiago de Chile: Ediciones Fuego y Tierra.

Reszcynski, Katia, Paz Rojas y Patricia Barceló. 1991. Tortura y resistencia en Chile: estudio médico-político. Santiago de Chile: Editorial Emisión. 
Rojas, Emilio. 1989. Tejas verdes. Mis primeros tres minutos. Santiago de Chile: Editora Seminario 90.

Rojas, Fabiola. 2013. El trauma social de la tortura política en Chile: análisis a través de la historia de vida de una mujer víctima de prisión política y tortura, Tesis para optar al grado de Antropóloga Social, Universidad Bolivariana, Santiago de Chile.

Rojas, Ma Eugenia. 1988. La represión política en Chile: los hechos. Madrid: Iepala Editorial.

Rojas, Paz. 1989. Persona, Estado, Poder: Estudio sobre Salud Mental. Chile 1973-1989. Vol. I. Santiago de Chile: Codepu.

Rojas, Paz. 1996. Persona, Estado, Poder: Estudio sobre Salud Mental. Chile 1990-1995. Vol. II. Santiago de Chile: Codepu.

Rojas, Paz. 2004. "Torturas. Romper el silencio". En De la tortura no se habla: Agüero Versus Meneses, editado por Patricia Verdugo. Santiago de Chile: Catalonia, 161-180.

Roth, Kenneth y Minky Worden (eds.). 2005. Torture: Does it Make us Safer? Is it Ever OK? New York: The New Press.

Rynard, Paul y David Shugarman (eds.). 2000. Cruelty and Deception: The Controversy over Dirty Hands in Politics. Ontario: Peterborough. Broadview Press.

Sánchez, Luis Alberto. 2014. A la sombra de Tejas Verdes. Memoria de un sobreviviente. Santiago de Chile: Akhilleus.

Santelices, Patricio. 2008. Me acompaña por favor. Una visión singular de la dictadura de Pinochet: historias humanas en el campo de concentración del Estadio Nacional de Santiago de Chile, relatadas por un ex preso político. Madrid: Guillomía Comunicación Gráfica.

Santos-Herceg, José. 2015. "Tortura: todo es cuerpo". Revista de la Academia 20: 27-45.

Sartre, Jean Paul. 1958. "Una Victoria". Prólogo a La Tortura de Henri Alleg. Buenos Aires: Ediciones del Pórtico.

Semana. 2014, 9 de septiembre. "Conmoción en Chile por 'pacto de silencio' a 41 años del Golpe". Recuperado el 26 de agosto de 2017 de http://www.semana.com/mundo/ articulo/aniversario-del-golpe-de-estado-chileno-llega-con-noticia-de-pacto-de-silencio-militar/402413-3

Shue, Henry. 2005. "Torture in dreamland: disposing of the ticking bomb". Case Western Reserve Journal of International Law. 37: 231-239.

Schuffer, Cynthia. 2016. "Resistir y traicionar. Las modulaciones del silencio y la voz en testimonios de la represión". En Revisitar la Catástrofe. Prisión Política en el Chile dictatorial, editado por Carolina Pizarro Cortés y José Santos Herceg. Santiago de Chile: Pehuén.

Sepúlveda, Víctor. 2016. "Semblanzas del torturador pinochetista". En Revisitar la Catástrofe. Prisión Política en el Chile dictatorial, editado por Carolina Pizarro Cortés y José Santos Herceg. Editorial Pehuén, Santiago de Chile.

Steinhoff, Uwe. 2010. “Defusing the Ticking Social Bomb Argument: The Right to Self-defensive Torture". Global Dialogue 12(1).

Sussman, David. 2005. “What's Wrong with Torture?" Philosophy and Public Affairs 33: 1-33.

Tricot, Tito. 1990. "La tortura: agencia primaria del terror". En Tortura: Aspectos médicos, psicológicos y sociales. Prevención y tratamiento. Santiago de Chile: Equipo de Salud Mental-DITT del Comité de Defensa de los Derechos del Pueblo (Codepu).

Verdugo, Patricia (ed.). 2004. De la tortura no se habla: Agüero versus Meneses. Santiago de Chile: Catalonia.

Vidal, Hernán. 2000. Chile: poética de la tortura política. Santiago de Chile: Mosquito Editores.

Vuskovic, Sergio. 2006. Un viaje muy particular, comentario. Valparaíso: Universidad de Playa Ancha.

Walzer, Michael. 1973. "Political Action: The Problem of Dirty Hands". Philosophy \& Public Affairs 2(2): 160-180.

Westin, Charles. 1994. Tortura y Existencia. Santiago de Chile: Ediciones Universidad Academia de Humanismo Cristiano.

Wijze, Stephen de. 2007. "Dirty Hands: Doing Wrong to do Right". En Politics and Morality, editado por Igor Primoratz. Nueva York: Palgrave Macmillan, 3-19. 
Wijze, Stephen de. 2018. “The Problem of Dmocratic Dirty Hands: Citizen Complicity, Responsibility, and Guilt". The Monist 101(2): 129-149.

Yuing Alfaro, Tuillang. 2016. "La tortura: un espacio entre el silencio y el decir". En Revisitar la Catástrofe. Prisión Política en el Chile dictatorial, editado por Carolina Pizarro Cortés y José Santos Herceg. Santiago de Chile: Pehuén.

Zapata, Pamela. 2008. Efectos emocionales, afectivos y sociales de la privación de libertad y tortura por motivos políticos en Chile de 1973 a 1990. Tesis para optar al grado de doctora en Psicología Clínica y de Salud, Universidad de Salamanca, España.

Recibido: 14 de enero de 2019

Aceptado: 24 de julio de 2019

José Santos Herceg es Licenciado en Filosofía por la Pontificia Universidad Católica de Chile y doctor en Filosofía por la Universität Konstanz, Alemania. En la actualidad es investigador del Instituto de Estudios Avanzados (IDEA) de la Universidad de Santiago de Chile. Ha publicado como autor los libros Conflicto de Representaciones. América Latina como lugar para la filosofía (2010), Cartografía Crítica. El quehacer profesional de la filosofía en Chile (2015), Lugares espectrales. Topología testimonial de la prisión política en Chile, (2019). Ha compilado textos como Revisitar la catástrofe. Prisión política en el Chile pinochetista (2015) junto a Carolina Pizarro, Liberación, Interculturalidad e Historia de las Ideas, Pensamiento Filosófico en América latina (2013), Nuestra América inventada. América latina en los pensadores chilenos (2012), Escritos Republicanos (2011) junto con María José López, Interculturalidad e Integración. Desafíos pendientes para América Latina (2007) y La Universidad chilena desde los extramuros. Luís Scherz García (2005). Correo electrónico: jose.santos@usach.cl 